\title{
Saccadic and manual reaction times to stimuli initiated by eye or finger movements
}

\author{
THOMAS M. GRAEFE and JONATHAN VAUGHAN \\ Hamilton College, Clinton, New York 13323
}

\begin{abstract}
Three variables that might influence oculomotor and finger movement reaction times to visual stimuli were combined factorially: the response used to produce each stimulus, the response used to report the target stimulus, and the delay between the stimulus-producing response and the stimulus onset. Stimulus onset delay and the type of stimulus-producing response affected reaction time significantly, but the response used to report the stimulus did not. The stimulus onset delay affected both manual and oculomotor reaction times in a manner similar to that of the warning stimulus in conventional reaction time experiments. Thus, the greater facilitation of oculomotor latency that has been observed in previous visual search experiments cannot be attributed to reaction time warning-stimulus effects.
\end{abstract}

In a recent experiment (Vaughan \& Graefe, 1977; see also Vaughan, in press), perceptual and oculomotor factors that might determine fixation duration in search were compared. A delay was imposed between the beginning of each fixation and the onset of the visual stimulus to be observed during that fixation. If the time required for information processing set the lower limit on fixation durations, then the end of each fixation would be synchronized with stimulus onset, regardless of delay. The time between stimulus onset and the next saccade (oculomotor latency) would be constant over the delay range. On the other hand, if oculomotor processes set the lower limit of fixation duration, and processing time were negligible, then fixation duration would be unaffected by the delay, and oculomotor latency would decrease linearly as stimulus onset delay increased. The major effect observed by Vaughan and Graefe (1977) was that oculomotor latency decreased more than manual reaction time, as stimulus onset delay was varied over a $150-\mathrm{msec}$ range, suggesting a greater role for oculomotor than perceptual processes in determining fixation duration.

It is well known that a warning stimulus can facilitate reaction time, even to a stimulus in another sensory modality, and that lengthening the foreperiod between a warning stimulus and the target stimulus decreases disjunctive reaction time (Bertelson, 1967; Drazin, 1961). The effect of the delay on reaction time in the Vaughan and Graefe (1977) experiment was within the values that might be expected if the saccade served as such a warning stimulus. Therefore, if a foreperiod effect is to be completely ruled out as the explanation

This research was supported by Grant MH-26303 from the National Institute of Mental Health to the second author. Thomas M. Graefe is now at the Department of Psychology, Princeton University, Princeton, New Jersey 08540. Reprint requests may be sent to him or Jonathan Vaughan, Department of Psychology, Hamilton College, Clinton, New York 13323. of the oculomotor latency results, two characteristics of that experiment which are not typical of reaction time foreperiod experiments must be explored. First, the putative foreperiod (the stimulus onset delay) started with a subject-produced event (a saccade), rather than an experimenter-produced one. Second, the response measure in the earlier study was an eye movement rather than a finger movement. In summary, it is important to know if subject-produced foreperiod signals have different effects than those presented by an experimenter; or if eye movements are more affected by foreperiod effects than are hand movements.

The present experiment was designed to examine the difference between the manual and oculomotor stimulus-initiating responses, and the difference between manual and oculomotor target-reporting responses. At the same time, the range of delays imposed was manipulated in an attempt to distinguish saccadic suppression and reaction time effects: By hypothesis, effects dependent on a psychological foreperiod effect should vary with the range of delays used, as has been shown in other reaction time experiments (Drazin, 1961); whereas effects due to a physiological process such as saccadic suppression should be invariant regardless of the delay range.

\section{METHOD}

\section{Subjects}

Five undergraduate students (two females) served in the experiment. Subjects were run on each of the conditions, in the order given below, until three sessions of greater than $90 \%$ accuracy had been obtained in that condition.

\section{Apparatus}

The horizontal electrooculogram (EOG) was recorded, using Grass E4S silver-silver chloride electrodes applied with Grass EC2 electrode cream, as close as possible to the external canthi. Electrode-to-electrode resistance was established at 3,000 ohms or less. An earclip electrode served as ground reference. The amplified (Grass P-18 dc amplifier) EOG was recorded by a 
PDP-8/E computer. Subjects were lightly restrained in a headrest with a chin support.

The computer generated stimuli on a Tektronix oscilloscope with P31 phosphor (32-msec delay time) located $27 \mathrm{~cm}$ in front of the subject. The two stimulus locations were located $7.5 \mathrm{deg}$ on either side of the center of the oscilloscope screen and were presented on a background of about $16 \mathrm{~cd} / \mathrm{m}^{2}$. Two stimuli were made up of 12 dots from a 4 by 6 dot matrix, forming the character " $X$ " or "O." Stimuli subtended an angle of $.6 \mathrm{deg}$ horizontally and $1.0 \mathrm{deg}$ vertically, and their brightness was adjusted for comfortable visibility without persistence on the oscilloscope screen. The subject operated a microswitch with the thumb of his or her preferred hand. Red and green pilot lights mounted below the oscilloscope provided performance feedback after each trial.

\section{Procedure}

Three variables that might influence oculomotor and finger reaction times were combined factorially: the response producing the stimulus (initiating response-eye or finger), the response used to report the target stimulus (target response-eye or finger), and the delay range ( 0 to $150 \mathrm{msec}$ or 0 to $300 \mathrm{msec}$ ). Thus, there were eight conditions in the experiment, which are labeled according to the initiating response, target response, and delay range: FF-150, FF-300, EF-150, EF-300, EE-150, EE-300, FE-150, FE-300. On each trial, the initiating response started the stimulus onset delay (foreperiod), after which a target ("O") or nontarget ("X") stimulus was presented for 500 msec or until a target response occurred. Subjects were instructed to make the target response to the target stimulus, and to refrain from making a response to the nontarget stimulus.

When the initiating response was a finger movement, a stationary fixation point was provided at the location of the stimulus, near the right side of the oscilloscope screen. The subject stared at the spot, and pressed the microswitch to begin the stimulus onset delay. When the initiating response was an eye movement, a second fixation point was presented near the left side of the screen separated from the first by $10 \mathrm{deg}$; the subject began a trial by staring at the left fixation point and pressing the microswitch; when the saccade to the right fixation point was made, the stimulus onset delay was begun.

When the target response was a finger movement, the subject released the microswitch on detection of the target stimulus. When the target response was an eye movement, the subject made a saccade to a fixation point $12 \mathrm{deg}$ to the left of the stimulus.

Depending on the delay range, the stimulus onset delay for each target stimulus was selected from the values $0,30,60$, 90,120 , and $150 \mathrm{msec}$ or $0,60,120,180,240$, and $300 \mathrm{msec}$. The stimulus onset delay used for each target stimulus was also used for the nontarget stimuli of the immediately preceding trials. A random order of target and nontarget stimuli was used such that the probability of a target stimulus on each trial was approximately .5 .

\section{RESULTS}

Reaction time for correct trials of the eight conditions are plotted in Figure 1. Analysis of variance was performed on the data from all conditions combined, using only those delay values $(0,60$, and $120 \mathrm{msec})$ that were common to all conditions. The main effects of stimulus onset delay $[F(2,8)=93.16, p<.0001]$ and type of initiating response $[\mathrm{F}(1,4)=25.31, \mathrm{p}<.01]$ were significant. None of the interactions met significance using a conservative test for interactions in repeated-measures designs (Winer, 1962, p 123).

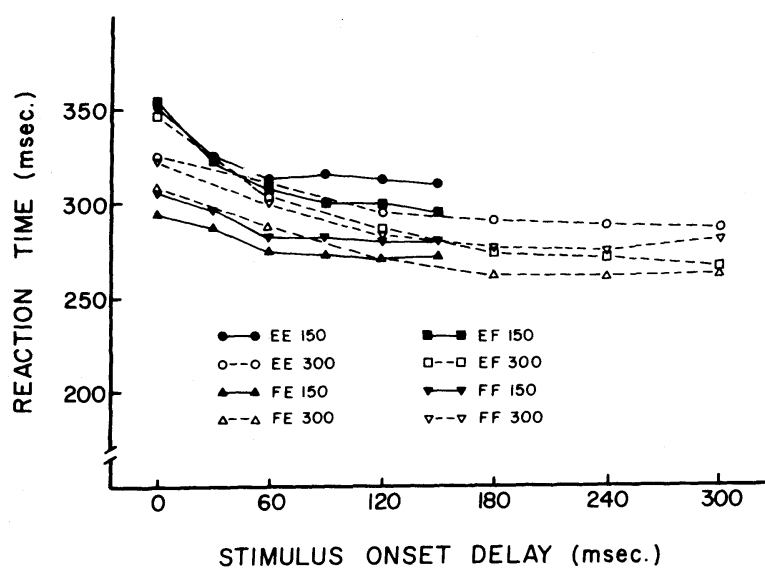

Figure 1. Reaction time for each of the conditions of the experiment. The first letter of each condition indicates the initiating response (which was an eye movement or a finger movement), the second letter indicates the target-reporting response (eye or finger movement), and the number indicates the delay range $(0$ to $150 \mathrm{msec}$ or 0 to $300 \mathrm{msec})$.

\section{DISCUSSION}

In studies in which warning stimuli have been observed to decrease disjunctive reaction time, the slope relating reaction time to the duration of the warning foreperiod varies from -.16 to -.26 over a 0 - to $50-\mathrm{msec}$ range (Bertelson, 1967; Bertelson \& Tisseyre, 1968, 1969; Davis \& Green, 1969). Saslow (1967) measured saccadic reaction time to a displaced target preceded by a visual warning stimulus, and found the slope of reaction time as a function of foreperiod duration to be -.22 over the 0 - to $150-\mathrm{msec}$ range. In the present experiment, the slope of the reaction time function for the $150-\mathrm{msec}$ range conditions was -.25 . Thus, the effect observed for subjectinitiated delay is consistent with previous studies of foreperiod effects, whether an eye movement or a finger movement initiated the response.

The failure of this experiment to show any difference in the effects of stimulus onset delay between finger or oculomotor responses supports the conclusion that the effect of stimulus onset delay on oculomotor latencies as found in the Vaughan and Graefe (1977) study was not due to warning-stimulus effects. Furthermore, those conditions in which the initiating response was a saccade (EE-150, EE-300, EF-150, and EF-300), while slower, show no more effect of the warning stimulus than those in which it was a finger movement. Finally, conditions with the longer $(300-\mathrm{msec})$ range of stimulus onset delays appear to reach asymptote later than the shorter range conditions. This is consistent with a foreperiod effect of interpretation of the data of this experiment (and of the reaction time data of Vaughan \& Graefe, 1977), since Drazin (1961) showed that foreperiod effects vary with the range of delays used.

\section{REFERENCES}

Bertelson, P. The time course of preparation. Quarterly Journal of Experimental Psychology, 1967, 19, 272-279.

Bertelson, P., \& Tisseyre, F. The time-course of preparation with regular and irregular foreperiods. Quarterly Journal of Experimental Psychology, 1968, 20, 297-300.

Bertelson, P., \& Tisseyre, F. The time-course of preparation: Confirmatory results with visual and auditory 
warning signals. Acta Psychologica: Attention and Performance II, 1969, 30, 145-154.

DAvis, R., \& GREEN, F. A. Intersensory differences in the effect of warning signals on reaction time. Acto Psychologica: Attention and Performance II, 1969, 30, 155-167.

DRAzIN, D. H. Effects of foreperiod, foreperiod variability and probability of stimulus occurrence on simple reaction time. Journal of Experimental Psychology, 1961, 62, 43-50.

SASLOW, M. G. Effects of components of displacement-step stimuli upon latency for saccadic eye movement. Journal of the Optical Society of America, 1967, 57, 1024-1029.
VAUGhaN, J. Control of visual fixation duration in search. In J. W. Senders, D. F. Fisher, \& R. A. Monty (Eds.), Eye movements and the higher psychological functions. Hillsboro, N.J: Lawrence Erlbaum, in press.

Vaughan, J., \& Graefe, T. M. Delay of stimulus presentation after the saccade in visual search. Perception \& Psychophysics, 1977, 22, 201-205.

WINER, B. J. Statistical principles in experimental design. New York: McGraw-Hill, 1962.

(Received for publication October 31, 1977.) 